\title{
LAMINAR NATURAL CONVECTION ABOVE A HORIZONTAL LASER BEAM $\dagger$
}

\author{
RONALD D. BOYD \\ Fluid and Thermal Sciences Department, Sandia Laboratories, \\ Albuquerque, NM 87185, U.S.A. \\ and \\ Charles M. Vest \\ Department of Mechanical Engineering, University of Michigan, \\ Ann Arbor, MI 48103, U.S.A.
}

(Received 30 July 1979 and in revised form 2 October 1980)

\begin{abstract}
The steady laminar natural convective plume above a horizontal laser beam has been studied. The plume, which is caused by absorption of thermal energy from the beam, is threc-dimensional.

The three-dimensionality is a consequence of mass continuity and the variation in the thermal energy absorption in the propagation direction. Flow visualizations have verified the three-dimensionality in that a significant velocity component, in a direction opposite to that of laser beam propagation, was observed.

The problem is reduced by similarity analysis to a system of ordinary differential equations which are solved numerically for the Prandtl number, $\mathrm{Pr}=1.0$. Integral approximations are also presented for $\mathrm{Pr}=$ $0.7,1.0,10.0$ and 100.0 . The effect of $P r$ on the velocities, and temperature boundary layer thicknesses is discussed in detail.
\end{abstract}

\section{NOMENCLATURE}

A.T., defined to be an adiabatic line along which energy is transferred from the decaying line source to the asymptotic region (regime II);

b, constant dimensionless scaling parameter which is related to the laser power generation;

$C_{p}, \quad$ specific heat of the fluid at constant pressure;

$F^{\prime}, \quad$ dimensionless $y$ - or vertical-component of velocity defined in equation (5);

$f^{\prime}, \quad$ dimensionless z- or axial-component of velocity defined in equation (5);

Gr, Grashof number defined in equation (5);

$g$, gravitational acceleration;

$k$, thermal conductivity of the fluid;

$m$, dimensional similarity parameter, with units of [length $]^{-1}$ which is related to the fluid absorptivity;

$m z_{0}$, dimensionless reference length in the $z^{-}$ direction for streamline projections (one of two parameters to be varied for each projection);

$n$, dimensionless similarity parameter defined in equation (8);

$P, \quad$ dynamic pressure;

$P_{0}, \quad$ peak power of the laser beam;

$\mathrm{Pr}, \quad$ Prandtl number of the fluid, $v \kappa^{-1}$;

† This work was supported by the Department of Mechanical Engineering at the University of Michigan and the U.S. Department of Energy.

$\ddagger$ A U.S. Department of Energy facility.

U.S. Government copyright.
$T$, local temperature excess relative to the ambient temperature;

$T_{0}, \quad$ reference temperature defined in equation (5);

$u$, velocity component in the $x$ - or plume width-direction;

V, velocity vector;

$v$, velocity component in the $y$-or verticaldirection ;

w, velocity component in the $z$ - or axialdirection;

$\left(x / x^{*}\right)$, dimensionless $x$-direction coordinate for streamline projections;

$x$, lateral or plume width coordinate;

$Y$, vertical or plume height coordinate in the asymptotic region (regime II, see Fig. 1);

$y, \quad$ vertical or plume height coordinate;
$Z, \quad$ axial or plume length coordinate in the asumptotic region (regime II, see Fig. 1);

$Z_{0}$, axial distance over which thermal energy is convected from the decaying line source to regime II (see Fig. 3);

$z$ axial or plume length coordinate (laser propagation direction);

$\alpha, \quad$ absorptivity of the fluid medium at the wavelength of the laser beam;

$\beta, \quad$ thermal expansivity of the fluid;

$\nabla, \quad$ vector differential operator;

$\delta_{1}$, dimensionless $y$-component velocity boundary layer thickness;

$\delta_{2}$, dimensionless thermal boundary layer thickness;

$\delta_{3}$, dimensionless $z$-component velocity boundary layer thickness;

$\eta$, similarity independent variable defined in 


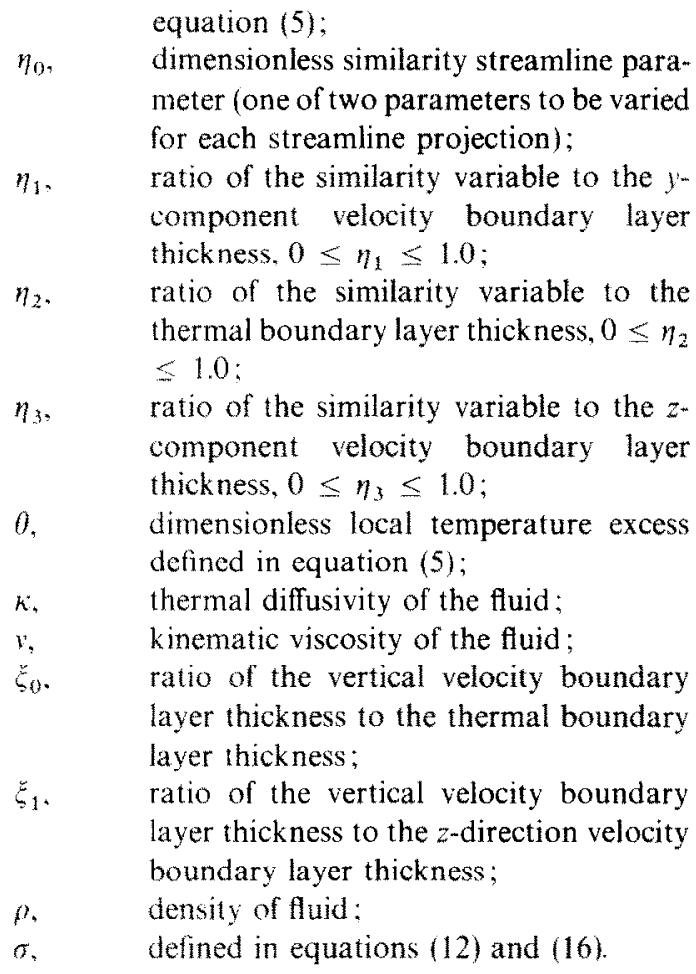

\section{IVTRODUCTION}

LAMINAR natural convective flow above a horizontal laser beam results from absorption by the fluid of energy from the beam $[1,2]$. Livingston [1] has given the most complete theoretical account, to date, of natural convective cooling of a fluid medium in the vicinity of a horizontal laser beam. He considered a uniform vertical forced flow through a beam whose thermally-induced optical distortion was determined by matching the forced flow solution to the wellknown solution for a natural convection plume above a uniform line source of energy. $p_{r}=\frac{5}{9}$ was used as an approximation for air. No direct comparisons were made between forced and natural convection.

The laminar natural convection plume above a uniform horizontal line source of energy has been investigated by many authors [3-6] and formulated in an optimum manner by Gebhart et al. [3]. Fujii [4] presented one of the most comprehensive accounts of the laminar flow above horizontal line and point sources.

In the present paper we present an analysis of the laminar natural convection plume above a thermal line source which decays exponentially along its length. This models the flow above a horizontal laser beam in an absorbing fluid. In addition to its general theoretical interest, this analysis will be useful in structuring a solution of the flow in the beam itself for prediction of therntal blooming of high-powered continuous wave laser beams.

\section{FORMULATION}

Consider the flow induced in a fluid due to absorp- tion of thermal energy from a horizontal laser beam which propagates through it. The energy absorption will vary, to first approximation, exponentially along the direction of beam propagation. Hence, sufficiently far above the horizontal laser beam, the flow can be modeled as a natural convection plume caused by an exponentially-decaying horizontal line source of en. ergy. To distinguish it from a uniform line source, it will be referred to as the decaying line source

In the steady laminar plume above a decaying line source, not only are there vigorous vertical and weaker lateral entraining velocity components, there is also a significant axial component of velocity. The quanitative analysis of the flow regime above a horizontal laser beam, therefore, requires a three-dimensiona! analysis. The coordinate system for the formulation is given in Fig. 1.

\section{Assumptions}

The usual Prandtl boundary layer approach is used; that is, all gradients such as $\partial^{2} / \partial y^{2}$ and $\partial^{2} / \partial z^{2}$ will be neglected relative to $\partial^{2} / \partial x^{2}$ in the asymptotic region above the decaying line source (regime II). In addition. the following assumptions are made

(1) The Boussinesq approximation applies, that is, a temperature-induced change in the density is only significant in the body force term.

(2) All other fluid properties are constant.

(3) All flow regimes are laminar.

(4) The local thermal energy increase due to compression work is negligible.

(5) Viscous dissipation is negligible.

(6) The shift and/or deflection in the laser beam due to thermal blooming does not significantly affect flow regime II.

(7) The effect of the irrotational flow outside the plume is neglected.

(8) The dynamic pressure gradient, $\nabla P$, is negligible (see [7 and 8]).

\section{Governing equations}

Based on the above assumptions, the governing equations for the plume flow in the asymptotic region (regime II) above a horizontal laser beam, with quiescent surroundings, are given by

$$
\begin{gathered}
\frac{\partial u}{\partial x}+\frac{\partial u}{\partial t}+\frac{\partial w}{\partial z}=0 \\
\frac{\partial p}{\partial x}=0 \\
u \frac{\partial t}{\partial x}+v \frac{\partial v}{\partial y}+w \frac{\partial t}{\partial z}=v \frac{\partial^{2} t}{\partial x^{2}}+\beta g T \\
\frac{\partial w}{\partial x}+v \frac{\partial w}{\partial y}+w \frac{\partial w}{\partial z}=v \frac{\partial^{2} w}{\partial x^{2}} \\
u \frac{\partial T}{\partial x}+v \frac{\partial T}{\partial y}+w \frac{\partial T}{\partial z}=\kappa \frac{\partial^{2} T}{\partial x^{2}}
\end{gathered}
$$




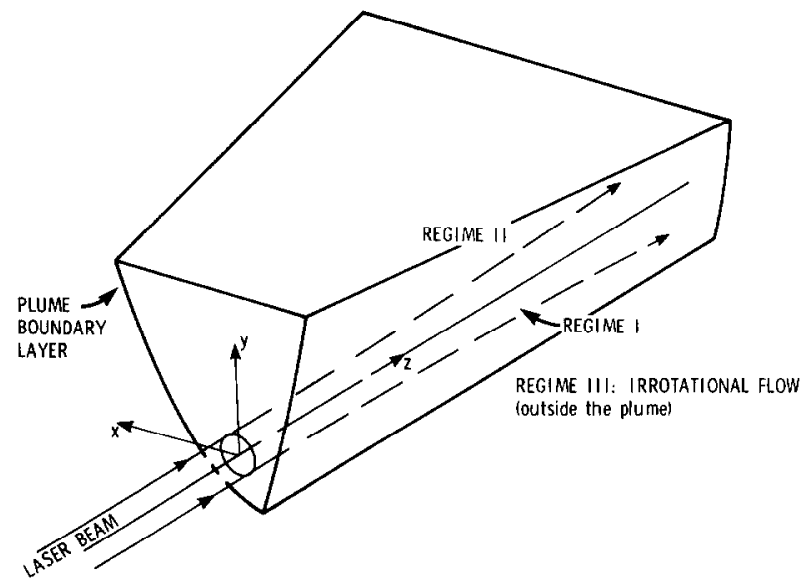

Fig. 1. Thermal plume flow regimes above a horizontal laser beam.

which are applicable for large values of the Grashof number. The boundary conditions for the plume flow are

$x=0 ; \quad \frac{\partial v}{\partial x}=0=\frac{\partial w}{\partial x} ; \boldsymbol{u}=0=\frac{\partial T}{\partial x} ;$ and $T=$ finite

$x=\infty: \quad v=0=w ; \frac{\partial T}{\partial x}=0 ;$ and $u=$ finite

$z=\infty: \quad v=0=w ;$ and $\frac{\partial T}{\partial x}=0$.

The above equations are valid for [8]

$$
G r \geq \varepsilon^{-4}
$$

where $\varepsilon$ is a small positive parameter given by

$$
\varepsilon^{2}=O\left(\frac{v}{L_{0} v_{0}}\right)
$$

and $L$ and $v_{0}$ are the characteristic reference length and velocity in the $y$-direction. Equations (3) and (4) are valid when the buoyancy force, vertical inertia, and viscous forces are of comparable magnitudes.

The partial differential equations (1) and (2) can be simplified to a set of ordinary differential equations when the following similarity transformations are used [8]:

$$
\begin{aligned}
\eta & =b G r^{(n+1) / 6} x Y^{-1} \mathrm{e}^{(m / 2) Z} \\
v & =b^{2} v G r^{(n+1) / 3} Y^{-1} \mathrm{e}^{m Z} f^{\prime}(\eta) \\
w & =b^{2}(v / m) G r^{(n+1) / 3} Y^{-2} \mathrm{e}^{m z} f^{\prime}(\eta) \\
u & =-\left(\frac{1}{2}\right) b v G r^{(n+1) / 6} Y^{-1} \mathrm{e}^{(m / 2) Z} U(\eta) \\
U(\eta) & =(n+1) F+(n-1) \eta F^{\prime}+f+\eta f^{\prime} \\
T & =b^{4} T_{0} G r^{[(2 / 3) n-(1 / 3)]} \mathrm{e}^{2 m z} \theta(\eta)
\end{aligned}
$$

where

$$
\begin{aligned}
G r & =\beta g T_{0} Y^{3} v^{-2} \\
T_{0} & =\frac{\alpha P_{0}}{k} \\
m & <0 .
\end{aligned}
$$

The prime (e.g. $\left.F^{\prime}\right)$ denotes differentiation with respect to $\eta$, which is the dimensionless similarity variable. The quantity $b$ is an unknown scaling factor which is related to the properties of the fluid and the power generation of the laser beam. The quantity $m$ is related to the absorption coefficient of the fluid. After the similarity transformation from equation (5) are made in the governing equations and boundary conditions, the latter are simplified to the following form:

$$
\begin{gathered}
F^{\prime \prime \prime}-n\left(F^{\prime}\right)^{2}-f^{\prime} F^{\prime}+\frac{1}{2}(n+1) F F^{\prime \prime} \\
+\frac{1}{2} f F^{\prime \prime}+\theta=0 \\
f^{\prime \prime \prime}-\left(f^{\prime}\right)^{2}-(n-1) f^{\prime} F^{\prime}+\frac{1}{2} f f^{\prime \prime} \\
+\frac{1}{2}(n+1) F f^{\prime \prime}=0 \\
\theta^{\prime \prime}+\operatorname{Pr}\left[\frac{1}{2}(n+1) F \theta^{\prime}-(2 n-1) F^{\prime} \theta\right. \\
\left.+\frac{1}{2} f \theta^{\prime}-2 f^{\prime} \theta\right]=0
\end{gathered}
$$

where the boundary conditions are

$$
\begin{aligned}
& \eta=0: F=0-f, F^{\prime \prime}=0=f^{\prime \prime} \text { and } \theta=1.0 \\
& \eta=\infty: F^{\prime}=0=f^{\prime} \text { and } \theta=0 .
\end{aligned}
$$

Following the procedure used by Gebhart et al. [3], for the uniform line source problem, $\theta(0)$ is assumed arbitrarily to equal 1.0 . These investigators noted that this is the optimum computational approach for solving the applicable differential equations. Many other procedures involving normalization (except that 
of normalizing the centerplane velocity) will either result in the addition of an extra equation or an additional unknown boundary condition to the numerical computation (cf. [3] with [4] and [6]).

Following the procedure of Brand and Lahey [6], the thermal energy equation (equation $(6 \mathrm{c})$, was integrated over the width of the plume, i.e., $\eta=-x$ to $x$. After the boundary conditions are enforced, a condition is obtained that defines the quantity, $n$. which appears throughout equations (5) and (6)

$$
n-\frac{1}{5}=-\frac{\int_{0}^{5} f^{\prime} \theta \mathrm{d} \eta}{\int_{0}^{x} F^{\prime} \theta \mathrm{d} \eta}
$$

The quantity, $n$, is an eigenvalue which is determined from the Prandt number of the fluid and the boundary conditions for the plume flow. Since $m$ and $w$ are $<0$ (this is verified below) and since $t$ and $T$ are $>0$, it is noted that $f^{\prime}, \theta$ and $F^{\prime}$ are all $>0$. The right hand side of equation ( 9 ) is therefore negative, and hence the quantity $n$ must be less than or equal to $1 / 5$, i.e. $n \leq 1 / 5$. When $n$ is equal to $1 / 5$, the numerator of equation (9) must vanish. This could result from two physical situations: (1) the $z$-vclocity component is zero, i.e., $f^{\prime}$ $=0=w$; or (2) a reverse flow exists above the decaying line source, i.e. above the laser beam. When $f^{\prime}$ or $w$ equal zero, there is no z-direction flow. This cannot be the case since flow visualizations were made of the plume above a horizontal laser beam and clearly show a $z$-velocity component (see Figs. 2(a), (b) and (c)). In addition, no reverse flow was observed. It was, therefore, concluded that $n$ does not equal $1 / 5$, but

$$
n<\frac{1}{5}
$$

Equations (5) through (8) reduce to those for the uniform line source when $m=0$ or $n=1 / 5$.

\section{Global thermal energy equation}

In two-dimensional and axisymmetrical plume flows, it is possible to write the global conservation of energy in terms of the total power generated by the power source and the energy convected and conducted across a given control surface, e.g. see $[4,5,9]$. This global conservation of thermal energy usually serves two purposes: (1) the parameter $n$ can be determined explicitly; and (2) the scaling parameter $b$ can be specified in terms of the total power gencration. Although it is possible to write such an equation for the flow in regime II (see Fig. 1), it is not possible to use it to determine explicitly the unknown parameters $n$ and $b$. The reason is that because of the threedimensionality of the flow, we do not know a priori the point of origin, along the line source, of thermal energy which is transported across the control volume at its boundary $y=Y, z=Z+Z_{0}$. Hence, we must write the conservation of energy for the control volume shown in Fig. 3 with $Z_{0}$ as a parameter

$$
\begin{aligned}
& \frac{1}{2} \int_{x+Z, \alpha}^{x} \frac{\alpha}{\rho C_{p}} \mathrm{e}^{-x z} P_{0} \mathrm{~d} z \\
& =\int_{2}^{x} \int_{x=y}^{x} v T \mathrm{~d} x \mathrm{~d} z .
\end{aligned}
$$

Based on physical grounds, it appears reasonable that $v T \delta_{1}\left(\delta_{1}\right.$ is a dimensionless $y$-velocity component boundary layer (thickness) is proportional to exp $(-\alpha z)$. This means that the local energy transported vertically decays in the same manner in which energy is absorbed by the fluid from the laser beam. Using this and enforcing the conditions of similarity, equation (10) can be simplified to

$$
h^{5}=\left[2 \operatorname{Pr} \int_{0}^{x} F^{\prime} \theta \mathrm{d} \eta\right]^{1}
$$

and

$$
\begin{gathered}
m=-\frac{2}{5} x \\
Z_{0}=-\alpha^{-1} \ln \left[G r^{(16)(5 n-1)}\right] .
\end{gathered}
$$

Equation (11a) provides an expression for the scaling parameter $b$ in terms of the Prandtl number and a dimensionless integral of the total energy convected vertically in the plume. Equation (11b) defines the quantity, $m$, in terms of the absorptivity of the fluid. Equation $(11 \mathrm{c})$ is a relationship for the axial distance over which energy is transported from a point on the decaying line source to a control surface located at $z=$ $Z$. Note that the parameter $n$ remains in the formulation as an eigenvalue.

\section{Integral formulation}

An integral analysis was used to obtain approximate solutions to equations (6) through (8). Polynomials were used to approximate the profiles of all dependent variables. The profile approximations are constructed to satisfy the boundary conditions and then forced to satisfy various integrals of the governing equations. For the applicable boundary conditions, it is found that the integral analysis must include three unknown boundary layer thicknesses [8]. The profile approximations selected for $F, f$ and $\theta$ are

$$
\begin{aligned}
& F=A\left(\eta_{1}^{5}-\frac{10}{3} \eta_{1}^{3}+5 \eta_{1}\right)=A G \\
& f=\sigma\left(\eta_{3}^{5}-\frac{10}{3} \eta_{3}^{3}+5 \eta_{3}\right)=\sigma Q \\
& \theta=\omega\left(\eta_{2}^{4}-2 \eta_{2}^{2}+1\right)=\omega H \\
& \eta=\delta_{1} \eta_{1}=\delta_{2} \eta_{2}=\delta_{3} \eta_{3} .
\end{aligned}
$$

Here, $0 \leq \eta_{1} \leq 1 ; 0 \leq \eta_{2} \leq 1$; and $0 \leq \eta_{3} \leq 1$; and $\dot{\partial}_{1}$ and $\delta_{3}$ are boundary layer thicknesses for velocities and $w$, and $\delta_{2}$ is the thermal boundary layer thickness. Since the $y$ - and $z$-components of velocity decrease monotonically with increasing values of $\eta$, it has been assumed that $f^{\prime \prime}\left(\delta_{3}\right)=0=F^{\prime \prime}\left(\delta_{1}\right)$. Equation (6) is evaluation at $\eta=0$ and after simplifications are made, 

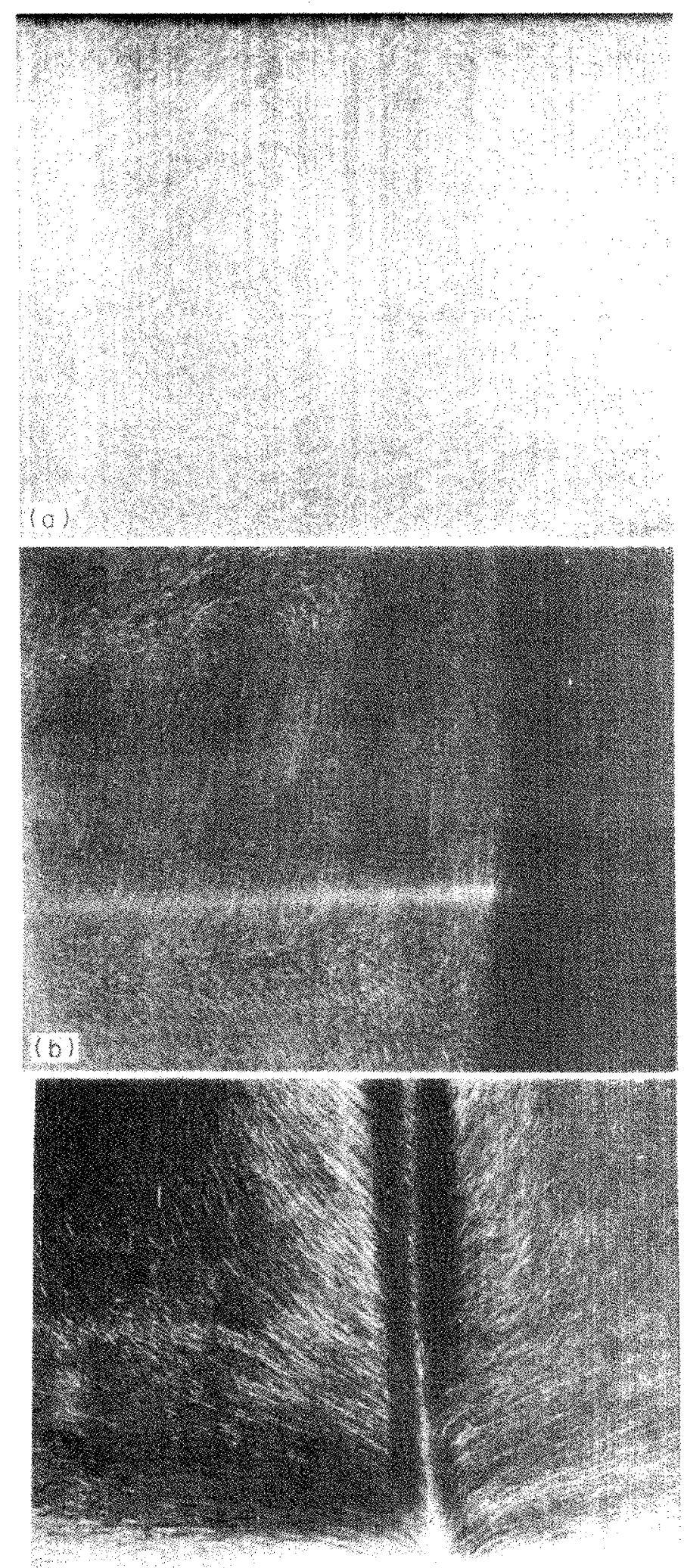

(c:

Fig. 2(a). Streakline projection, in the $x$ y plane, due to encrgy absorption from and laser beam (blocked briefly during exposure). Beam is directed ou: a: the pite.

(Fluid is water in these projections.)

Fic. 2(b). Streakline projection, in the $y$ z plane, due to energy absorption from a berizing $1.70 \mathrm{~mW}, \mathrm{He} \mathrm{Ne}$ laser beam. The laser beam is directed from right to left. Note that the line of stagnation of the vertical velocity is below the laser beam.

Fig. 2(c). Streakline projection, in the $x-z$ plane, due to energy absorption from a horizontal, $200 \mathrm{~mW}$, argon laser beam. The laser beam is directed from the bottom to the top of the photograph. 
the following results are obtained:

$$
\begin{aligned}
& -20 \pi_{3}-25 n-25 \xi_{1} \pi_{1}+\pi_{2}=0 \\
& 20 \pi_{3} \quad 25 \pi_{1} \xi_{1}^{-1}-25(n-1) \xi_{1}^{-2}=0 \\
& 2 \operatorname{Pr}^{-1} \pi_{3} \xi_{0}^{2}+5\left(n-\frac{1}{2}\right)+5 \pi_{1} \xi_{1}=0
\end{aligned}
$$

where $\xi_{0}$ and $\xi_{1}$ are boundary layer thickness ratios which are defined by

$$
\xi_{0}=\frac{\delta_{1}}{\delta_{2}} \text { and } \xi_{1}=\frac{\delta_{1}}{\delta_{3}} \text {. }
$$

In addition, $\pi_{2}$ is related to the ratio of the buoyancy body force to the $y$-component of inertia force associated with $v$, i.e.

$$
\pi_{2}=\left.n \frac{\beta g T}{v(\partial v / \partial y)}\right|_{x=0}=\omega \frac{\delta_{1}^{2}}{A^{2}} .
$$

Further, the quantity, $\pi_{1}$, is equal to the ratio of the stream functions at $\eta=x$, and is defined by

$$
\pi_{1}=\frac{f\left(\delta_{3}\right)}{F\left(\delta_{1}\right)}=\frac{\sigma}{A} \text {. }
$$

Finally, the quantity, $\pi_{3}$, is defined as

$$
\pi_{3}=A^{-1} \delta_{1}^{-1} \text {. }
$$

The remaining equations necessary for completion of the integral formulation are obtained by integrating each of the governing equations, from equation (6), over the appropriate boundary layer thickness

$$
\begin{gathered}
\left(n+\frac{1}{3}\right) I_{1}+\xi_{1} \pi_{2} I_{2}-\frac{2}{3} \pi_{2} \xi_{0}^{-1} I_{3}=0 \\
{\left.\left[2 \pi_{3} \xi_{1} Q^{\prime \prime}+(n+1) G Q^{\prime}+\pi_{1} Q Q^{\prime}\right]\right|_{\eta_{3}=1}} \\
-3 \pi_{1} I_{4}-(3 n-1) \xi_{1}^{-1} I_{5}=0 \\
\left(n-\frac{1}{5}\right) I_{6}+\pi_{1} \xi_{1} I_{7}=0
\end{gathered}
$$

where all quantities such as $I_{k}(k=1,2,3, \ldots)$ represent integrals of convective or body force terms and are given in the Appendix. Equations (18a) and (18b) can be solved for $\pi_{1}$ and $n$ in terms of the other unknowns (see equation (A8)).

\section{RESULTS AND CONCIUSIONS}

\section{Numerical computations}

A numerical solution of equations (6) through (8) was computed for $\operatorname{Pr}=1.0$. The numerical integration procedure is based on the Hamming's modified predictor-corrector method $[10]$ and the iterative procedure is based on the sequential simplex method [11]. The numerical procedure consists of converting the boundary value problem to an initial value problem by systematically guessing the conditions $F^{\prime}(0)$ and $f^{\prime}(0)$. Unfortunately, in addition to not knowing $F^{\prime}(0)$ and $f^{\prime}(0)$, the quantity $n$ is not known explicitly, so a search of a complicated parameter space is required.

For all numerical computations, a residual error function was defined as the linear sum of the absolute values of $F^{\prime}, f^{\prime}$ and $\theta$ and their derivatives at $\eta=5$. The definition of the quantity $n$ (equation (8)) was also included as part of the residual function. The residual function must be zero when the exact solution is found. As an independent check on the accuracy of the computations, the integrals of the $y$ - and z-momentum equations ((6a) and (6b)) were evaluated and found to be very near zero, providing evidence that the procedure has converged close to the exact solution.

The computed profiles for $F^{\prime}, f^{\prime}$ and $\theta$, for $\operatorname{Pr}=1.0$. are given in Fig. 4. The numerical computations are approximate since $f^{\prime}(x)$ did not precisely converge to zero as $\eta$ became very large. The condition, $f^{\prime}(x)=0$.

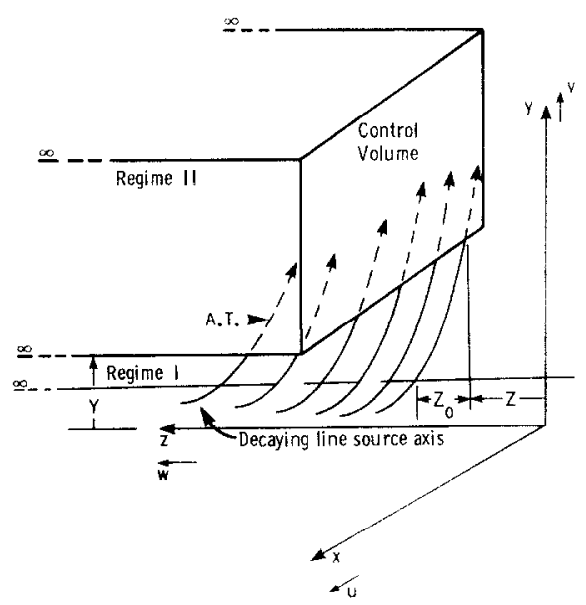

Fig. 3. Control volume for global energy balance above the horizontal decaying line source model; A.T. $\equiv$ Adiabatic Trajectory (see nomenclature).

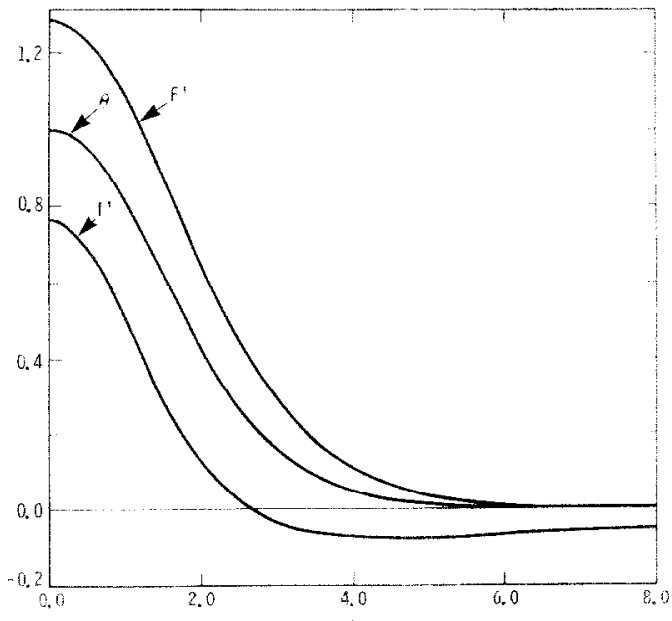

FIG. 4. Results from numerical computations for the dimen. sionless profiles of the temperature excess and velocity components in the plume above a horizontal decaying line source with $\mathrm{Pr}=1.0: n=-0.24916$. 
results from the requirement that $u(\infty, y, z)$ must remain finite. In the numerical computations, $f^{\prime}$ approached a small negative number as $\eta$ became large. An asymptotic analysis [8] of $F^{\prime}, \theta$ and $f^{\prime}$ shows that all these quantities must become asymptotically small as $\eta$ approaches infinity. The difficulty in the numerical computations is attributed primarily to the uncertainty of the quantity $n$. Since $n$ appears throughout the governing equations, its effect on the solution is critical.

A more accurate solution would require consideration of the interaction with the irrotational flow outside the plume. In fact, in the flow visualizations of the $x-z$ plane, it was observed that at the edge of the plume, the axial $(z-)$ component of velocity is not equal to zero, but is slightly negative. This implies that $f^{\prime}(\infty)$ is greater than zero (note that $m<0$ ) and that higherorder effects due to the external flow must be considered (e.g. [12] and [13]).

\section{Integral analysis}

Equations (13) and (18) form a system of non-linear algebraic equations with unknowns: $n, \pi_{1}, \pi_{2}, \pi_{3}, \xi_{0}$ and $\xi_{1}$. The sequential simplex optimization procedure [11] was used to solve the algebraic equations. This procedure required two independent variables $\left(\xi_{1}\right.$ and $\xi_{2}$ ). A residual error function was defined as the sum of equations (13a) and (13b). The residual function was minimized after repeated iterative computations. The constraints on the iterative procedure are

$$
\pi_{1}, \pi_{2}, \pi_{3} \text { and }\left(\frac{1}{5}-n\right)>0 .
$$

Profiles for functions associated with the $y$ - and $z$ components of velocity and the temperature are presented in Figs. 5(a) -5(c), for various values of the Prandtl number, $P r$. The magnitude of the vertical component above the decaying line source decreases with an increase in the Prandtl number, as it does in the case of a uniform line source. However, the axial component of velocity, $w$, increases with an increase in $P r$, if $P r \leq 10$, but decreases with an increase in $P r$, if $P r$ $\geq 10$. The latter decrease in $w$ is due to viscous diffusion effects. The local temperature gradient increases throughout the plume as $P r$ increases.

The effects of the diffusion of energy and momentum vary with $P r$ and can be evaluated by considering how the boundary layer thicknesses vary with $P r$. Both the dimensionless vertical velocity and thermal boundary layer thicknesses decrease continually as $\mathrm{Pr}$ increases from 0.7 to 100.0 . This indicates that $x$-direction diffusion of vertical momentum and thermal energy is becoming increasingly important as $\operatorname{Pr}$ increases. However, the dimensionless axial velocity boundary layer thickness increases slowly as $P r$ increases from 0.7 to 100.0 . This indicates that $x$-direction diffusion of axial momentum is approximately constant for at least a two-order-of-magnitude change in the Prandtl number. Finally, for $1.0 \leq P r \leq 10.0, \xi_{0}$ is near 1.0 $( \pm 10 \%)$ which indicates that for this range of $P r$, the

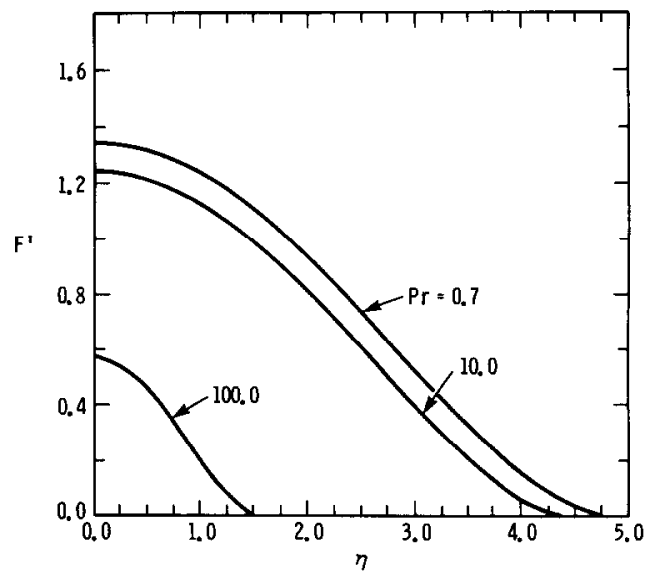

FiG. 5(a). Integral approximation profiles for the dimensionless vertical velocity component in the plume above a horizontal decaying line source, with the Prandtl number as a parameter.

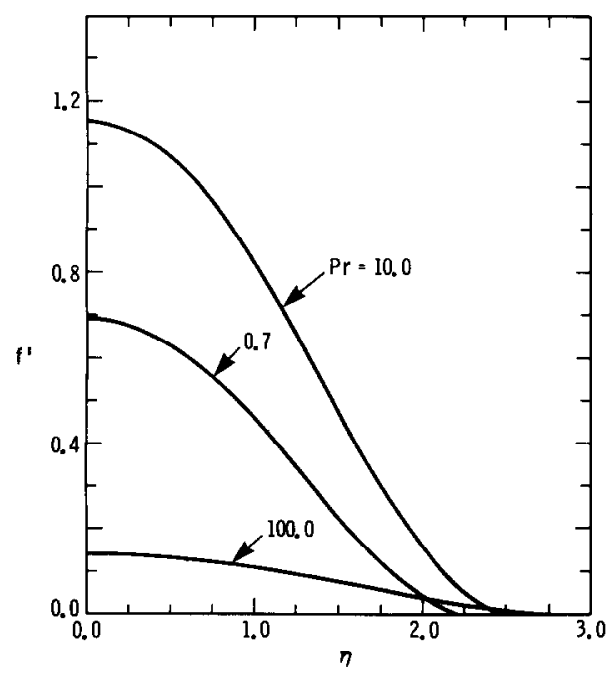

FIG. 5(b). Integral approximation profiles for the dimensionless axial velocity component in the plume above a horizontal decaying line source, with the Prandtl number as a parameter.

thermal and the vertical velocity boundary layer thicknesses are approximately equal. A summary of the integral approximation results is presented in Table 1.

To display the predicted fluid motion, we assumed that all boundary layer thicknesses were equal for $\mathrm{Pr}$ $=1.0$. This assumption simplifies the algebra and requires that the dimensionless axial velocity, $f^{\prime}$, and axial shear stress, $f^{\prime \prime}$, be non-zero at the edge of the boundary layer. The streamline projections in the $x-z$ plane and the boundary layer are presented in Fig. 6. Note that the flow is in a direction opposite to that of laser beam propagation. The slight flow reversal near the edge of the boundary layer is a result of the boundary conditions at $\eta=\delta_{3}$, which must be related to the vortex flow outside the plume. 


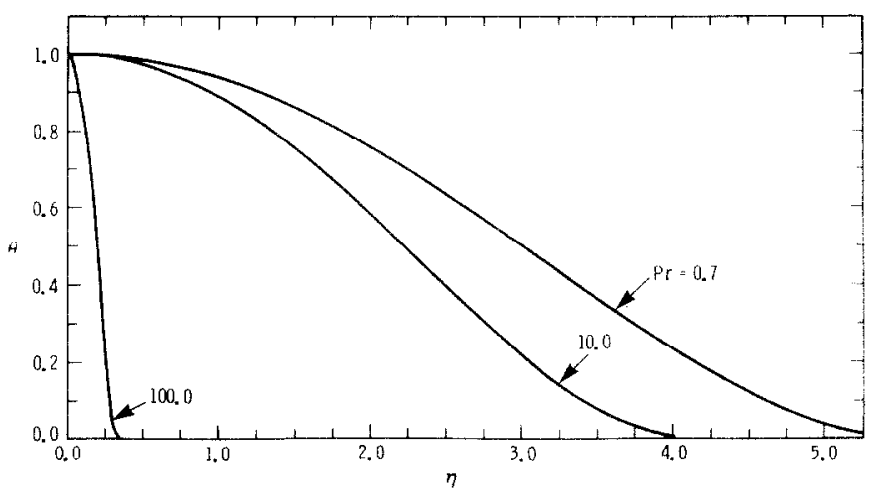

FIG. 5(c). Integral approximation profiles for the dimensionless temperature excess in the plume above a horizontal decaying line source, with the Prandtl number as a parameter

\section{DISCUSSION}

Some qualitative comparisons of the threedimensional flow above a decaying line source with the two-dimensional flow above a uniform line source are useful. Since the quantity $n$ is less than one-fifth, the temperature in the plume will decay faster in the vertical direction above the decaying line source than above the uniform line source. In cases where $n>0$, the vertical component of velocity above the decaying line source will increase more slowly above the decaying line source than above the uniform line source. For $n<0$, the vertical component of velocity decreases, with increasing $y$, above the decaying line source. As $\mathrm{Pr}$ increases, some trends are similar for both line sources: (1) the vertical velocity decreases throughout the plume; (2) the thermal and vertical velocity boundary layers decrease in thickness; and (3) the ratio of the vertical velocity boundary layer thickness to thermal boundary layer thickness increases continuously.

Finally, a conceptual description of the decaying line source will be given to supplement the above discussion. If the decaying line source is interpreted as a series of colinear point generators of decreasing strength, one realizes that the vertical and entraining components of velocity will be greater for the point of higher power. The entraining axial velocity, due to the point of higher power, will be greater and opposite in sense (in the axial or $z$-direction) than the entraining velocity of the adjacent weaker power generating point. The result is a small but finite component of velocity in the negative $z$-direction. When this effect is integrated over the length of the decaying line source, the result is a significant axial component of velocity. Therefore, the axial velocity component is a consequence of continuity, and is controlled by the local laser beam power generation and the effects of viscous diffusion.

Table 1. Results from the integral approximation for the decaying line source: $\theta(0)=1.0$

\begin{tabular}{|c|c|c|c|c|}
\hline $\operatorname{Pr}$ & 0.7 & 1.0 & 10.0 & 100.0 \\
\hline$\check{\zeta}_{0}$ & 0.885 & 0.930 & 1.10 & 4.59 \\
\hline $\begin{array}{l}\xi_{1} \\
\xi_{1}\end{array}$ & 2.14 & 201 & 1.81 & 0.52 \\
\hline$n$ & -0.0841 & -0.145 & -0.435 & -0.0455 \\
\hline$\pi_{1}$ & 0.240 & 0.289 & 0.509 & 0.459 \\
\hline$\pi_{2}$ & 13.8 & 14.4 & 16.1 & 76.5 \\
\hline$\pi_{3}$ & 0.153 & 0.169 & 0.193 & 3.57 \\
\hline$\sigma$ & 0.317 & 0.359 & 0.579 & 0.0821 \\
\hline$A$ & 1.32 & 1.24 & 1.13 & 0.178 \\
\hline$\delta_{1}$ & 4.91 & 4.72 & 4.56 & 1.56 \\
\hline$\dot{\delta}_{2}$ & 5.55 & 5.07 & 4.13 & 0.340 \\
\hline$\delta_{3}$ & 2.29 & 2.32 & 2.51 & 2.95 \\
\hline$F^{\prime}(0)$ & 1.34 & 1.31 & 1.24 & 0.571 \\
\hline$f^{\prime}(0)$ & 0.69 & 0.772 & 1.15 & 0.139 \\
\hline$U(\infty)$ & 2.03 & 1.89 & 1.62 & 0.336 \\
\hline$\frac{\pi_{2}}{\left(\pi_{1} \xi_{1}\right)^{2}} \sim \frac{\theta(0)}{\left[f^{\prime}(0)^{2}\right]}$ & 52.1 & 41.9 & 18.8 & 1293.0 \\
\hline$\xi_{1} \pi_{1} \sim \frac{f^{\prime}(0)}{F^{\prime}(0)}$ & 0.515 & 0.586 & 0.926 & 0.243 \\
\hline$\frac{\pi_{2}}{n}=\left.\frac{\beta g T}{v(\partial v / \partial y)}\right|_{x=0}$ & -164.5 & -99.2 & -37.0 & -1679.0 \\
\hline
\end{tabular}




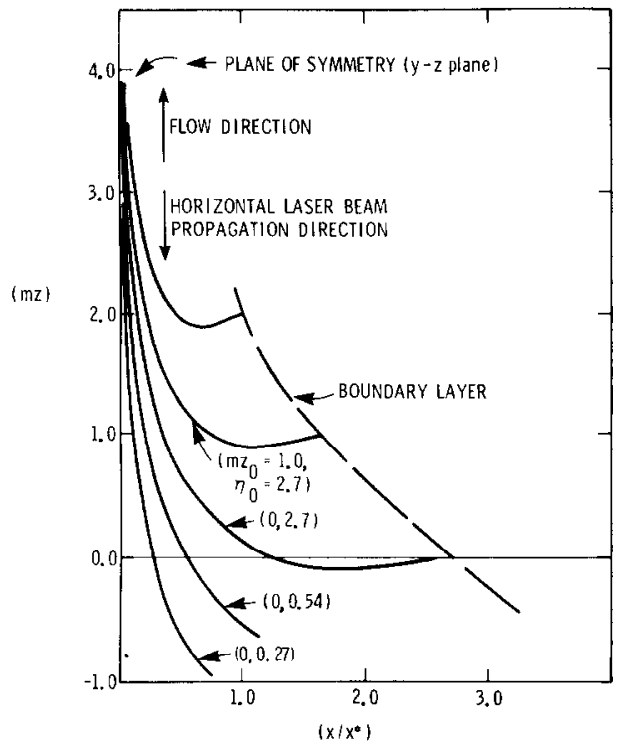

FIG. 6. Streamline projections in the $x-z$ plane of the plume above a horizontal decaying line source, with $\mathrm{Pr}=1.0$ and $\xi_{0}$

$$
=\xi_{1}=1.0 \text {. }
$$

Acknowledgement-The first author wishes to acknowledge support from the Department of Mechanical Engineering, at the University of Michigan for financial support through teaching and research fellowships.

\section{REFERENCES}

1. P. M. Livingston, Thermally induced modification of a high power CW laser beam, Appl. Optics 10(2), 426-436 (1971).

2. R. D. Boyd and C. M. Vest, Onset of convection due to horizontal laser beams, Applied Physics Letters 26(6), 287-288 (1975)

3. B. Gebhart, L. Pera and A. W. Schorr, Steady laminar natural convection plumes above a horizontal line heat source, Int. J. Heat Mass Transfer 13, 161-171 (1970).

4. T. Fujii, Theory of the steady laminar natural convection above a horizontal line heat source and a point heat source, Int. J. Heat Mass Transfer 6, 597-606 (1963).

5. C.-S. Yih, Laminar free convection due to a line source of heat, Trans. Am. Geophy. Un. 33(5), 669-672 (1952).

6. R. S. Brand and F. J. Lahey, The heated laminar vertical jet, J. Fluid Mech. 29 (Part 2), 305-315 (1967).

7. Y. Jaluria, Natural Convection Heat and Mass Transfer, pp. 22-150. Pergamon Press, New York (1980).

8. R. D. Boyd, Natural convection induced by a horizontal laser beam, Ph.D. Thesis. University of Michigan (1976).

9. C.-S. Yih, Free convection due to a point source of heat, Proc. 1st U.S. Nat. Congr. Appl. Mech., pp. 941-947 (1951).
10. IBM Programmer's Manual, Systems/360 Scientific Subroutine Package - Version III, pp. 337-343 (1970).

11. G. S. Beveridge and R. S. Schechter, Optimization: Theory and Practice, pp. 367-383. McGraw-Hill, New York (1970).

12. C. A. Hieber and E. J. Nash, Natural convection above a line heat source: higher-order effects and stability, Int. J. Heat Mass Transfer 18, 1473-1479 (1975).

13. N. Riley, Free convection from a horizontal line source of heat, Z. Angew. Math. Phys. 25, 817-838 (1974).

\section{APPENDIX}

Integrals of convective and body force terms

$$
\begin{aligned}
& I_{1}=\frac{640}{63} \\
& I_{2}=\begin{array}{ll}
\frac{40}{63} \xi_{1}^{4}-\frac{80}{21} \xi_{1}^{2}-\frac{80}{9}, & \xi_{1} \leq 1 \\
\frac{40}{63} \xi_{1}^{-5}-\frac{80}{21} \xi_{1}^{-3}+\frac{40}{3} \xi_{1}^{-1}, & \xi_{1}>1
\end{array}
\end{aligned}
$$

$$
\begin{aligned}
& I_{3}= \begin{cases}\frac{8}{15}, & \xi_{0} \geq 1 \\
\frac{1}{5} \xi_{0}^{5}-\frac{2}{3} \xi_{0}^{3}+\xi_{0}, & \xi_{0}<1\end{cases} \\
& I_{4}=\frac{640}{63} \\
& I_{5}=\begin{array}{l}
\xi_{1} I_{2} \\
I_{6}=\left\{\begin{array}{l}
\frac{8}{63} \xi_{0}^{-4}-\frac{16}{21} \xi_{0}^{-2}+\frac{8}{3}, \quad \xi_{0} \geq 1 \\
\frac{8}{63} \xi_{0}^{5}-\frac{16}{21} \xi_{0}^{3}+\frac{8}{3} \xi_{0},
\end{array} \xi_{0}<1\right.
\end{array}
\end{aligned}
$$

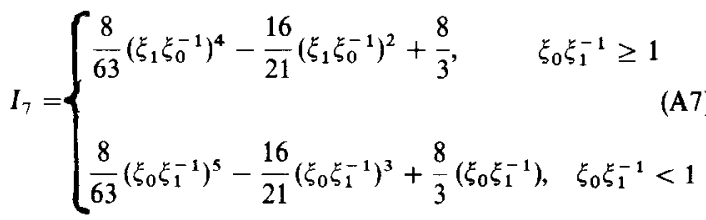

$\pi_{1}=D_{1} D^{-1}$ and $n=D_{2} D^{-1}$

where

$D=\xi_{1}^{-1}\left[I_{6} I_{7}^{-1}-I_{5} I_{4}^{-1}\right], \quad D_{1}=2 I_{6} I_{5}\left(15 \xi_{1}^{2} I_{4} I_{7}\right)^{-1}$

and

$D_{2}=I_{7}\left(5 I_{9} \xi_{1}\right)^{-1}-I_{5}\left(3 \xi_{1} I_{4}\right)^{-1}$.

\section{CONVECTION NATURELLE LAMINAIRE AU-DESSUS D'UN RAYONNEMENT LASER HORIZONTAL}

Résumé - On étudie le panache de convection naturelle, permanente, laminaire au-dessus d'un rayon laser horizontal. Le panache provoqué par l'absorption de l'énergie thermique du rayon est tridimensionnel. La tridimensionnalité est une conséquence de la continuité de la masse et de la variation de l'absorption de l'énergie dans la direction de propagation. Des visualisations d'écoulement ont vérifié cette tridimensionnalité car on observe une composante de vitesse dans la direction opposée à celle de la propagation du laser.

Le problème est réduit par une analyse de similitude à un système d'équations différentielles qui sont résolues numériquement pour le nombre de Prandtl $\operatorname{Pr}=1,0$. Des approximations intégrales sont aussi présentées pour $\operatorname{Pr}=0,7,1,10$ et 100. On discute en détail l'effet de $\operatorname{Pr}$ sur les épaisseurs des couches limites dynamique et thermique. 


\section{LAMINARE NATÜRLICHE KONVEKTION ÜBER EINEM HORIZONTALEN LASERSTRAHL}

Zusammenfassung - Untersucht wurde die stationäre laminare Auftriebsströmung durch natürliche Konvektion über einem horizontalen Laserstrahl. Die Auftriebsströmung, die durch Absorption thermischer Energie des Strahls verursacht wird, ist dreidimensional.

Die Dreidimensionalität folgt aus der Kontinuitätsgleichung und der Veränderung der thermischen Energieabsorption in Ausbreitungsrichtung. Durch Sichtbarmachung der Strömung wurde die Dreidimensionalität bestätigt, wobei eine bedeutende Geschwindigkeitskomponente in entgegengesetzter Richtung zur Laserstrahlausbreitung beobachtet wurde. Das Problem wird durch Ähnlichkeitsbetrachtung auf ein System gewöhnlicher Differentialgleichungen reduziert, die numerisch für die Prandtl-Zahl, $P r=1.0$ gelöst werden. Integrale Approximationen werden auch für $P_{r}=0,7 ; 1,0 ; 10,0$ und 100,0 angegeben. Der EinfluB von $\operatorname{Pr}$ auf die Geschwindigkeiten und Temperaturgrenzschichtdicken wird ausführlich erörtert.

\section{ЛАМИНАРНАЯ ЕСТЕСТВЕННАЯ КОНВЕКЦИЯ НАД ГОРИЗОНТАЛЬНЫМ ЛАЗЕРНЫМ ПУЧКОМ}

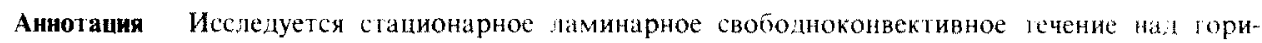
зонтальным лазерным пучком, мндуцированное поглощением тельовои энергин и: пучка. Трехмерность течения обьясняется законом неразрывноси массы и изменением пог 1онения в направлении распространения пучка. Она подгерждается также визуализаий потока набпю-

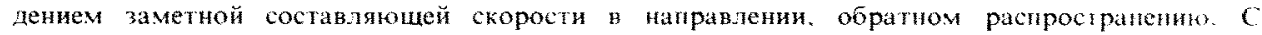
помопью автомодельных преобразований задаша сволится к системе обыкновенив лифференциальных уравнений, которые решантся численно для числа Прандтя $\operatorname{Pr}=1,0$. Препставлены лакже пнтегральные приближенные формулы лия $\mathrm{Pr}=0,7,1,0 ; 10,0$ и 100.0. Подробно обсужла-

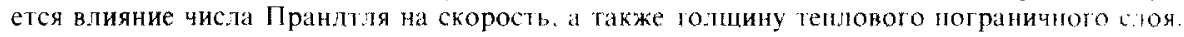

